\title{
Knoop microhardness and FT-Raman evaluation of composite resins: influence of opacity and photoactivation source
}

\author{
Luis Gustavo Barrotte Albino(a) \\ José Augusto Rodrigues(b) \\ Yoshio Kawano(c) \\ Alessandra Cassoni ${ }^{(b)}$
}

\footnotetext{
(a) Department of Restorative Dentistry, Graduate Division, Guarulhos University, Guarulhos, SP, Brazil.

(b) Department of Restorative Dentistry, Dental Research Division, Guarulhos University, Guarulhos, SP, Brazil.

(c) Department of Fundamental Chemistry, Chemistry Institute, Universidade de São Paulo - USP, São Paulo, SP, Brazil.
}

Declaration of Interests - The authors have no interest in any of the companies or products mentioned in this article.

\section{Corresponding author:}

Alessandra Cassoni

Guarulhos University - UnG

Pós-graduação em Odontologia

Praça Teresa Cristina, 229 - Centro

CEP: 07023-070

Guarulhos - SP - Brazil

E-mail: acassoni@prof.ung.br

Received for publication on Dec 08, 2010 Accepted for publication on Mar 04, 2011

\begin{abstract}
The aim of this study was to evaluate the degree of conversion by Knoop microhardness (KHN) and FT-Raman spectroscopy (FTIR) of one nanofilled (Filtek Supreme-3M-ESPE [FS]) and one microhybrid composite (Charisma-Heraeus-Kulzer $[\mathrm{CH}]$ ), each with different opacities, namely enamel, dentin, and translucent, which were photo-activated by a quartz-tungsten-halogen lamp (QTH) and a light-emitting diode (LED). Resin was bulk inserted into a disc-shaped mold that was $2.0 \mathrm{~mm}$ thick and $4 \mathrm{~mm}$ in diameter, obtaining 10 samples per group. KHN and FTIR values were analyzed by two-way ANOVA and Tukey's tests $(\alpha=0.05)$. Nanofilled resin activated by aED presented higher microhardness values than samples activated by a QTH for dentin opacity $(\mathrm{p}<0.05)$. The microhybrid resin showed no differences in KHN or FTIR values with different activation sources or opacity. The nanofilled dentin and enamel resins showed lower FTIR values than the translucent resin. The KHN values of the translucent resins were not influenced by the light source.
\end{abstract}

Descriptors: Composite Resins; Hardness; Spectrum Analysis; Light.

\section{Introduction}

The clinical performance of composite resin restorations depends on several factors, which may alter the physical-chemical properties of the resin; such properties include the concentration of monomer and filling particles and those related to the clinician's manipulation. ${ }^{1}$ Also, the quality of the light emitted by the curing units may affect monomer conversion and improved mechanical properties. ${ }^{2}$

Curing units activate the camphoroquinone, which is the photo-initiator most commonly present in resin composites that is sensitive to blue light in the wavelengths between 400 and $515 \mathrm{~nm} .{ }^{1,3-5}$ Commonly, curing units are composed of a halogen lamp that provides a white light spectrum filtered to produce a spectral output between 400 and $500 \mathrm{~nm}^{6}$ However, a wide spectrum of light is still emitted when this energy is spent. The light emitting diode (LED) curing units provide a narrow bandwidth of light with a wavelength of $470-490 \mathrm{~nm}$, which is capable of polymerizing the composite resin with less energy than the halogen lamp because LED light is close to the camphoroquinone excitation wavelength. ${ }^{4}$ 
The polymerization efficiency of a composite resin is influenced by the irradiation intensity, exposure time, and the light source. ${ }^{7}$ Concerns about these variables have led to several studies recently to determine the degree of conversion (DC) of dental composites. ${ }^{7-15}$ The sensitivity of molecular vibrational methods, such as infrared spectroscopy (FTIR) and Raman spectroscopy (FT-Raman), offers a direct approach to quantify the ratio of monomers' conversion into polymers; this quantification is accomplished by assessing the specific band positions and by comparing the residual unpolymerized aliphatic $\mathrm{C}=\mathrm{C}$ stretching band at $1640 \mathrm{~cm}^{-1}$ to the aromatic $\mathrm{C}=\mathrm{C}$ stretching band at $1610 \mathrm{~cm}^{-1}{ }^{8,9,16}$ Thus, the ratio of double carbon bonds that are converted into single bonds determines the DC of the resin composite. ${ }^{8,11-13,15}$ On the other hand, the hardness achieved by the polymerized composite is widely used as an indirect method of determining the quality of the light-initiated polymerization process. ${ }^{17}$

The light that initiates the polymerization may be absorbed or scattered through the body of the resin, jeopardizing the polymerization process. The lower transmittance of the light results in a low $\mathrm{DC}^{18}$ and consequently low microhardness, ${ }^{19}$ which is strongly influenced by the resin's opacity and its filler contents. ${ }^{6,18,20}$ It has been speculated that darker resins, which are more saturated in croma, need a higher density of light energy to reach an acceptable monomer conversion than do lighter colored resins. ${ }^{20}$ However, there is little information regarding the opacity and light influence in the conversion because translucent resins are frequently used to reproduce enamel, and opaque resins are frequently used to reproduce dentin with the same croma. ${ }^{21}$

The aim of this study was to evaluate the degree of conversion by Knoop microhardness (KHN) and FT-Raman spectroscopy (DC) of one nanofilled and one microhybrid composite, each with different opacities (enamel, dentin, and translucent), which were photo-activated by a QTH or a LED.

\section{Methodology}

One nanofilled and one microhybrid commercial composite resin, each with three different opacities related to their translucence, were selected for this study (Table 1).

Two light curing units with different light sources - a halogen source with a light intensity of $700 \mathrm{~mW} / \mathrm{cm}^{2}$ (Optilux 501 - Demetron/Kerr, Danbury, USA) and a LED source with an intensity of $1200 \mathrm{~mW} / \mathrm{cm}^{2}$ (Radii - SDI Limited, Victoria, Australia) - were used. The power density was measured with a radiometer (Demetron/Kerr, Danbury, USA). Table 2 presents the energy density calculated after multiplying the power density by the exposure time recommended by the manufacturers. ${ }^{22}$

\section{Specimen preparation}

A total of 120 specimens were prepared according to the twelve groups ( $\mathrm{n}=10$; Table 2$)$.

A two-part white polytetrafluoroethylene mold with a cylindrical window $(4 \mathrm{~mm}$ in diameter and $2 \mathrm{~mm}$ high) was placed on a $10 \times 120 \times 0.05-\mathrm{mm}$ Mylar strip (Polidental, Cotia, Brazil) on a matte black background and was kept stable with a metal ring. The composite was inserted in a single increment, and a second strip was placed on top of the unpolymerized material. A glass slide was put on top of the Mylar strip, and a $500 \mathrm{~g}$ load was applied for $30 \mathrm{~s}$ on the top of the mold to provide a smooth surface. The glass slide was removed before expos-

\begin{tabular}{|c|c|c|c|c|c|}
\hline \multirow{3}{*}{$\begin{array}{r}\text { Table } 1 \text { - Composite resin } \\
\text { materials evaluated and their } \\
\text { classification, composition, opacity } \\
\text { and lot number (No). }\end{array}$} & Material Manufacturer & Classification & Composition & Opacity & Lot No \\
\hline & $\begin{array}{l}\text { Filtek Supreme } \\
\text { (3M/ESPE, St. Paul, } \\
\text { USA) }\end{array}$ & Nanofilled & $\begin{array}{l}\text { Bis-GMA, Bis-EMA (6), UDMA, } \\
\text { TEGDMA, zirconia-silica nanocluster, } \\
\text { silica nanoparticles }\end{array}$ & $\begin{array}{l}\text { A2D } \\
\text { A2E } \\
\text { GT }\end{array}$ & $\begin{array}{l}5 \mathrm{AM} \\
7 \mathrm{EC} \\
7 \mathrm{BM}\end{array}$ \\
\hline & $\begin{array}{l}\text { Charisma } \\
\text { (Heraeus-Kulzer, } \\
\text { Hanau, Germany) }\end{array}$ & Microhybrid & $\begin{array}{l}\text { Bis-GMA, TEGDMA, barium } \\
\text { aluminum silicate and colloidal silica }\end{array}$ & $\begin{array}{l}\mathrm{OA} 2 \\
\mathrm{~A} 2 \\
\text { Incisal }\end{array}$ & $\begin{array}{l}010302 \\
010306 \\
010302\end{array}$ \\
\hline
\end{tabular}

Bis-GMA = bisphenol glycidyl methacrylate; Bis-EMA = bisphenol A polyethylene glycol diether dimethacrylate; $\mathrm{UDMA}=$ urethane dimethacrylate; TEGMA = triethylene glycol dimethacrylate. 


\begin{tabular}{|c|c|c|c|c|c|c|}
\hline \multirow{3}{*}{$\begin{array}{l}\text { Table } 2 \text { - Composite resins' } \\
\text { shades and photoactivation } \\
\text { sources, showing the calculated }\end{array}$} & & & & & & \\
\hline & \multirow{2}{*}{ Resin composite } & \multicolumn{4}{|c|}{ Groups } & \multirow{2}{*}{$\begin{array}{l}\text { Exposure } \\
\text { time }(\mathrm{s})\end{array}$} \\
\hline & & Halogen & Energy density $\left(\mathrm{J} / \mathrm{cm}^{2}\right)$ & LED & Energy density $\left(\mathrm{J} / \mathrm{cm}^{2}\right)$ & \\
\hline \multirow{6}{*}{$\begin{array}{r}\text { irradiation time and the energy } \\
\text { density }\left(\mathrm{J} / \mathrm{cm}^{2}\right) .\end{array}$} & \multirow{3}{*}{ Filtek Supreme (FS) } & $\mathrm{D}$ & 28 & D & 48 & 40 \\
\hline & & $\mathrm{E}$ & 14 & $\mathrm{E}$ & 24 & 20 \\
\hline & & $\mathrm{T}$ & 14 & $\mathrm{~T}$ & 24 & 20 \\
\hline & \multirow{3}{*}{ Charisma $(\mathrm{CH})$} & D & 28 & $\mathrm{D}$ & 48 & 40 \\
\hline & & $\mathrm{E}$ & 14 & $\mathrm{E}$ & 24 & 20 \\
\hline & & $\mathrm{T}$ & 14 & $\mathrm{~T}$ & 24 & 20 \\
\hline
\end{tabular}

$\mathrm{D}=$ Dentin; $\mathrm{E}=$ Enamel $; \mathrm{T}=$ Translucent.

ing the composite resin to light, and the light tip of each curing unit was centered on the specimen with no intervening space. ${ }^{8,19}$

\section{Degree of Conversion}

Five prepared specimens were evaluated immediately after light activation for each group. As a control, the spectra of five unpolymerized composites were analyzed for each group.

The DC of the side opposite to the irradiated surface of the specimens was determined by an RFS 100/S FT-Raman spectrometer (Bruker Optics, Billerica, USA) equipped with a liquid nitrogen-cooled germanium detector. The 1064-nm line of an aircooled Nd:YAG near-infra-red laser was used to excite the samples. ${ }^{8,10}$ The Raman spectra were obtained using 64 scans at a spectral resolution of $4 \mathrm{~cm}^{-1}$ and were analyzed by selecting a spectral region of $1000-2000 \mathrm{~cm}^{-1}$. The Raman spectrum obtained from the uncured (translucent) FS is represented in Figure 1.

The DC of each sample was determined by comparing the aliphatic carbon double bond peak with the aromatic component for the unpolymerized and polymerized states. ${ }^{9}$ The ratio between the aliphatic $\left(1640 \mathrm{~cm}^{-1}\right)$ and the aromatic $\left(1610 \mathrm{~cm}^{-1}\right)$ carbon double bond peaks was used to calculate the DC according to the following formula: $:^{8,11-13}$

$$
\text { DC }=[1-(\text { polymerized/unpolymerized })] \times 100
$$

\section{Knoop microhardness profile}

After polymerization, each specimen was re-

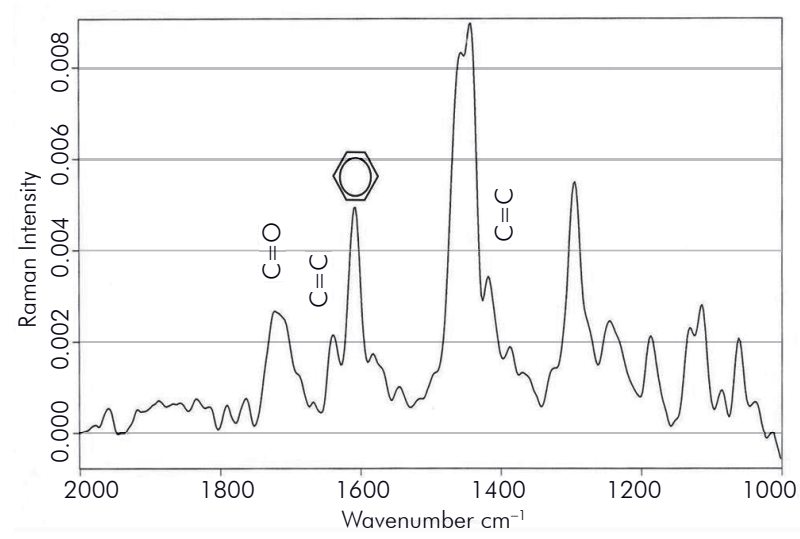

Figure 1 - FT-Raman spectrum of nanofilled composite (translucent) cured by halogen light $\left(14 \mathrm{~J} / \mathrm{cm}^{2}\right)$ with the main vibrational modes assigned: $\mathrm{C}=\mathrm{O}$ stretching mode at $1730 \mathrm{~cm}^{-1}$; the methacrylate $\mathrm{C}=\mathrm{C}$ stretching mode at $1640 \mathrm{~cm}^{-1}$; the $\mathrm{C}=\mathrm{C}$ stretching of the aromatic group at 1610 and $1452 \mathrm{~cm}^{-1}$.

moved from the mold and was stored in deionized water in light-proof containers for $24 \mathrm{~h}$ at a constant temperature of $37^{\circ} \mathrm{C}$. A Knoop diamond indenter was used to make five indentations in the center of the surface opposite to the light-irradiated surface of the specimen with a $25 \mathrm{~g}$ load for $20 \mathrm{~s}^{8,19}$ The mean of the five microhardness evaluations of each specimen was used as the specimen's microhardness value.

\section{Statistical analysis}

For each composite, a two-way analysis of variance was carried out, and the means of the Knoop microhardness values (KHN) and the degree of conversion were compared by a Tukey's interval calculated at a $95 \%$ confidence level. 


\section{Results}

\section{Knoop microhardness}

The data were submitted to a two-way ANOVA and to a Tukey's test $(\alpha=0.05)$ considering the factors of photoactivation source and resin opacity and their interaction.

There were statistically significant differences for the photoactivation source $(\mathrm{p}=0.001$; Table 3$)$ for the FS. There were no statistically significant differences for the resin opacity $(\mathrm{p}=0.982)$. Statistically significant differences were found in the interaction of the photoactivation source * resin opacity $(\mathrm{p}=0.003$, Table 3$)$ with a higher KHN for the dentin resin activated with the LED than that activated with the QTH.

No statistically significant differences were observed for photoactivation source $(\mathrm{p}=0.14)$, resin opacity $(p=0.52)$, or for the interaction of the photoactivation source * resin opacity $(\mathrm{p}=0.51$, Table 4) for the microhybrid resin.

\section{Degree of Conversion}

Figure 1 shows the representative FT-Raman spectra of the FS (translucent) cured by a halogen light $\left(14 \mathrm{~J} / \mathrm{cm}^{2}\right)$. Data were submitted to two-way ANOVA and to Tukey's test $(\alpha=0.05)$ considering the factors of photoactivation source and resin opacity and their interactions. The data obtained for the

Table 3 - Mean Knoop microhardness values (KHN) and standard deviations for each experimental group of nanofilled resin (FS) and a Tukey's post-hoc test.

\begin{tabular}{c|c|c|c}
\hline Source & Dentin & Enamel & Translucent \\
\hline QTH $(n=10)$ & $39.6 \pm 6.5 b A$ & $46.0 \pm 6.3 a A$ & $46.2 \pm 5.1 \mathrm{aA}$ \\
\hline $\operatorname{LED}(n=10)$ & $56.0 \pm 5.6 a A$ & $50.1 \pm 8.9 a A$ & $49.1 \pm 6.2 \mathrm{aA}$ \\
\hline
\end{tabular}

Means followed by the same capital letters in the row or lower case letters in the column are not statistically different $(p<0.05) ; n=$ number of samples.

Table 4 - Mean Knoop microhardness values (KHN) and standard deviations for each experimental group of microhybrid composites $(\mathrm{CH})$.

\begin{tabular}{c|c|c|c}
\hline Source & Dentin & Enamel & Translucent \\
\hline QTH $(n=10)$ & $22.8 \pm 2.9$ & $19.1 \pm 1.7$ & $19.6 \pm 3.30$ \\
\hline $\operatorname{LED}(n=10)$ & $24.1 \pm 3.6$ & $26.4 \pm 4.9$ & $21.9 \pm 3.8$ \\
\hline
\end{tabular}

DC and for the standard deviation for each experimental group are shown in Tables 5 and 6.

There were statistically significant differences for resin opacity $(\mathrm{p}<0.001$, Table 5$)$. The dentin and enamel resins showed a lower DC than did the translucent resin (FS). There were no statistically significant differences for photoactivation source $(\mathrm{p}=0.65)$ or for the interaction of the photoactivation source * resin opacity $(\mathrm{p}=0.17)$.

There were no statistical differences for the resin opacity $(\mathrm{p}=0.52)$, the photoactivation source $(\mathrm{p}=0.18)$, or for the interaction of the photoactivation source * resin opacity $(\mathrm{p}=0.88)$ for the $\mathrm{CH}$; the results are presented in Table 6.

\section{Discussion}

The advancement in LED technology is comparable with the advancement in computer technology. ${ }^{4}$ The quality of the polymerization process can influence the performance of composite resins and plays an important role in the success of dental restorations. ${ }^{7}$ This process may be predicted by the proportion of monomers effectively converted into polymers. This proportion is described as the degree of conversion and is usually evaluated by several methods, including the non-destructive technique Raman spectroscopy. ${ }^{8,16}$ The most important vibrational bands have been previously reported, ${ }^{9}$ and the

Table 5 - Mean DC (\%) of the nanofilled resin (FS) after activation and standard deviations, and the results of Tukey's test for the opacity factor.

\begin{tabular}{c|c|c|c}
\hline Source & Dentin & Enamel & Translucent \\
\hline QTH & $50.8 \pm 2.4$ & $55.3 \pm 4.6$ & $64.8 \pm 1.8$ \\
\hline LED & $55.7 \pm 4.3$ & $55.2 \pm 2.8$ & $63.8 \pm 5.6$ \\
\hline Opacity Factor $(n=10)$ & $53.4 \pm 3.0 b$ & $55.2 \pm 3.7 b$ & $64.3 \pm 4.0 \mathrm{a}$ \\
\hline
\end{tabular}

Means followed by the same lower case letters in the row are not statistically different $(p<0.05) ; n=$ number of samples.

Table 6 - Mean DC (\%) of the microhybrid resin $(\mathrm{CH})$ and standard deviations.

\begin{tabular}{c|c|c|c}
\hline Source & Dentin & Enamel & Translucent \\
\hline QTH $(n=10)$ & $46.5 \pm 5.8$ & $48.2 \pm 6.1$ & $47.8 \pm 7.3$ \\
\hline $\operatorname{LED}(n=10)$ & $44.4 \pm 2.2$ & $46.9 \pm 2.0$ & $45.7 \pm 1.8$ \\
\hline
\end{tabular}


Raman spectrum of the uncured FS, with the main vibrational modes assigned, is shown in Figure 1.

The nanofilled resin selected for the present study was Filtek Supreme. It is classified as a particulate, reinforced, polymer-based resin. ${ }^{23}$ Filtek Supreme has been described as having a $46.6 \%$ conversion at surface but only $38 \%$ DC at a $2-\mathrm{mm}$ thickness with the same nanofilled dentin resin; these data emphasize the decrease in light transmission that occurs throughout the composite resin. ${ }^{23}$ The DC of the nanofilled resin was influenced by its translucence in the present study. Thus, in this study, the translucent resin showed a higher DC than did the dentin or the enamel opacities. Presumably, there was high light scattering though the translucent resin because a higher transmittance of the light results in a higher $\mathrm{DC},{ }^{18}$ which is strongly influenced by the resin opacity and filler contents. ${ }^{6,18}$ For these reasons, composite resin with the dentin opacity needs to receive a higher exposure time to reach a similar DC of composite resin with enamel opacity (Table 5).

Because the radiant exposure is calculated as the product of irradiance and time of irradiation provided by the light unit, ${ }^{10}$ the results obtained using the LED light source are probably due to the generation of a high irradiance of this unit associated with the maximum absorption wavelength of the camphoroquinone.

Moreover, the absence of statistical differences in the degree of conversion in the microhybrid resin in function of opacity and photo-activation factors may be explained by the theory that above a certain energy density threshold, the power density does not influence the polymerization kinetics of the resin polymerization process. ${ }^{22}$ Moreover, above an irradiance of $10 \mathrm{~J} / \mathrm{cm}^{2}$, there is a tendency for the DC to stabilize. ${ }^{24}$ However, higher DCs lead to concerns because they promote higher shrinkage stress during polymerization, and there might be an increased risk of adhesive failures. ${ }^{13,24}$

The nanofilled resin (FS) showed an interaction of the studied factors. The dentin resin showed a statistically lower KHN when activated by the QTH (39.6 KHN) as compared to the group activated by the LED (56 KHN). An increase in irradiance leads to a higher hardness in the composite resin, ${ }^{10}$ and polymerization depends not only on the intensity of the light, but also on the total amount transmitted throughout the polymer. ${ }^{22}$ Thus, one possible reason for this difference may be related to the energy density of the LED associated with the pigments of the resin composite that were able to scatter the light emitted from the QTH.

It has been reported that the KHN of the A1 shade of a nanofilled composite (FS) was higher (52.3 KHN) than that of the A3 shade $(42.7 \mathrm{KHN})$ after activation by a QTH lamp, showing that the degree of conversion may be impaired by croma saturation. ${ }^{19}$ In another study, a $37.4 \mathrm{KHN}$ and a $48.6 \%$ degree of conversion were reported for the Filtek Supreme-A3 activated with a QTH lamp; these values were considerably lower than the values observed in the present study due to the saturation of the nanofilled resin chosen. ${ }^{8}$ The translucent resin (shade YT) showed no statistical differences between QTH or LED activation, and these results are similar to those of the present study, which showed similar KHN values independently of the light source. ${ }^{25}$

Higher KHN values at a 2-mm depth have been reported for Charisma samples activated by $\mathrm{LED}^{26}$ rather than by QTH. Nevertheless, these values are not in agreement with the values achieved in the present study; one probable explanation for this difference is the lower irradiance values in the prior study. ${ }^{26}$ In the present study, no differences related to opacity or photo-activation factors were observed for the microhybrid resin in the microhardness profiles or in the DC evaluation. One possible reason for this result is the presence of colloidal silica particles in the composite resin, which could cause dispersion of the incident light, thus decreasing the polymerization depth of the composite. ${ }^{13}$

Although the results were not statistically comparable, it was observed that the nanofilled resin showed the highest mean microhardness values of those tested. Furthermore, the present study highlights the influence of the amount of energy delivered on the degree of composite polymerization.

\section{Conclusions}

The microhardness values of the enamel and the 
translucent color of the nanofilled composite resin were not influenced by the light activation source. Further, the activation of the dentin shade by the LED resulted in higher microhardness values than did the QTH activation. The dentin and enamel shades of the nanofilled composite showed lower DCs than did the translucent shade. The microhy-

\section{References}

1. Price RB, Ehrnford L, Andreou P, Felix CA. Comparison of quartz-tungsten-halogen, light-emitting diode, and plasma arc curing lights. J Adhes Dent. 2003 Fall;5(3):193-207.

2. St-Georges AJ, Swift EJ, Thompson JY, Heymann HO. Irradiance effects on the mechanical properties of universal hybrid and flowable hybrid resin. Dent Mater. 2003 Jul;19(5):406-13.

3. Wiggins KM, Hartung M, Althoff O, Christine W, Mitra SB. Curing performance of new-generation light-emitting diode dental curing unit. J Am Dent Assoc. 2004 Oct;135(10):14719.

4. Kramer N, Lohbauer U, García-Godoy F, Frankenberger R. Light-curing units of resin-based composites in the LED era. Am J Dent. 2008 Jun;21(3):135-42.

5. Ramp LC, Broome JC, Merrie HR. Hardness and wear resistance of two composte cured with equivalent radiant exposure from low irradiance LED and QTH light-curing units. Am J Dent. 2006 Feb;19(1):31-6.

6. Rueggeberg FA, Ergle JW, Mettenburg DJ. Polymerization depths of contemporary light-curing units using microhardness. J Esthet Dent. 2000;12(6):340-9.

7. Lohbauer U, Rahiotis C, Krämer N, Petschelt A, Eliades G. The effect of different light-curing units on fatigue behavior and degree of conversion of a resin composite. Dent Mater. 2005 Jul;21(7):608-15.

8. Cassoni A, Ferla J de O, Shibli JA, Kawano Y. Knoop microhardness and FT-Raman spectroscopic evaluation of a resinbased dental material light-cured by an argon ion laser and halogen lamp: an in vitro study. Photomed Laser Surg. 2008 Dec;26(6):531-9.

9. Tsuda H, Arends J. Raman spectroscopy in dental research: a short review of recent studies. Adv Dent Res. 1997 Nov;11(4):539-47.

10. Silva EM, Poskus LT, Guimarães JGA. Influence of lightpolymerization modes on the degree of conversion and mechanical properties of resin composites: a comparative analysis between a hybrid and a nanofilled composite. Oper Dent. 2008 May-Jun;33(3):287-93.

11. Ferracane JL. Correlation between hardness and degree of conversion during the setting reaction of unfilled dental restorative resins. Dent Mater. 1985 Feb;1(1):11-4.

12. Gonçalves F, Calheiros FC, Witzel MF, Kawano Y, Braga RR. Effect of photoactivation protocol and radiant exposure brid composite showed no differences in microhardness values or in the degree of conversion for all of the experimental groups.

\section{Acknowledgements}

The authors would like to thank the 3M ESPE company for material support. on monomer conversion and flexural strength of a resin composite after water and ethanol storage. J Biomed Mater Res B Appl Biomater. 2007 Jul;82(1):89-92.

13. Calheiros FC, Braga RR, Kawano Y, Ballester RY. Relationship between contraction stress and degree of conversion in restorative composites. Dent Mater. 2004 Dec;20(10):939-46.

14. Emami N, Söderholm KJM. How light irradiance and curing time affect monomer conversion in light-cured resin composites. Eur J Oral Sci. 2003 Dec;111(6):536-42.

15. Schneider LFJ, Pfeifer CSC, Consani S, Prahl SA, Ferracane $\mathrm{JL}$. Influence of photoinitiator type on the rate of polymerization, degree of conversion, hardness and yellowing of dental resin composites. Dent Mater. 2008 Sep;24(9):1169-77.

16. Soh MS,Yap AU, Yu T, Shen ZX. Analysis of the degree of conversion of LED and Halogen lights using micro-Raman Spectroscopy. Oper Dent. 2004 Sep-Oct;29(5):571-7.

17. Yap AU, Soh MS, Han TT, Siow KS. Influence of curing lights and modes on cross-link density of dental composites. Oper Dent. 2004 Jul-Aug;29(4):410-5.

18. Leloup G, Holvoet PE, Bebelman S, Devaux J. Raman scattering determination of the depth of cure of light-activated composites: influence of different clinically relevant parameters. J Oral Rehabil. 2002 Jun;29(6):510-5.

19. Cassoni A, Ferla J de O, Albino LG, Youssef MN, Shibli JA, Rodrigues JA. Argon ion laser and halogen lamp activation of a dark and light resin composite: microhardness after longterm storage. Lasers Med Sci. 2010 Nov;25(6):829-34.

20. Aguiar FH, Lazzari CR, Lima DA, Ambrosano GM, Lovadino JR. Effect of light curing tip distance and resin shade on microhardness of a hybrid resin composite. Braz Oral Res. 2005 Oct-Dec;19(4):302-6.

21. Yu B, Lee YK. Translucency of varied brand and shade of resin composite. Am J Dent. 2008 Aug;21(4):229-32.

22. Gritsch K, Souvannasot S, Schembri C, Farge P, Grosgogeat B. Influence of light energy and power density on the microhardness of two nanohybrid composites. Eur J Oral Sci. 2008 Feb;116(1):77-82.

23. Rodrigues Jr SA, Scherrer SS, Ferracane JL, Bona AD. Microstructural characterization and fracture behavior of a microhybrid and a nanofilled composite. Dent Mater. 2008 Sep;24(9):1281-8. 
24. Calheiros FC, Daronch M, Rueggeberg FA, Braga RR. Influence of irradiant energy on degree of conversion, polymerization rate and shrinkage stress in an experimental resin composite system. Dent Mater. 2008 Sep;24(9):1164-8.

25. Gomes GM, Calixto AL, Santos FA, Gomes OM, D’alpino $\mathrm{PH}$, Gomes JC. Hardness of a bleaching-shade resin composite polymerized with different light-curing sources. Braz Oral Res. 2006 Oct-Dec;20(4):337-41.

26. Torno V, Soares P, Martin JMH, Mazur RF, Souza EM, Vieira S. Effects of irradiance, wavelength, and thermal emission of different light curing units on the Knoop and Vickers hardness of a composite resin. J Biomed Mater Res B Appl Biomater. 2008 Apr;85(1):166-71. 